\title{
9
}

Juan Puchalt Sanchis*

\section{LA EVOLUCIÓN DE LA ACTIVIDAD FERIAL EN ASIA-PACÍFICO}

La organización y celebración de ferias comerciales es una actividad de plena actualidad, que se extiende por la mayor parte de países. En este trabajo se estudia la actividad ferial en Asia-Pacífico para conocer su situación actual y su evolución en el periodo 2004-2014. Mediante el análisis estadístico y tomando como fuente la información de asociaciones internacionales de ferias, se obtienen interesantes conclusiones sobre sus características y comportamiento, tendencias e ideas valiosas para los agentes feriales y las empresas que puedan operar o participar en futuros eventos. La región analizada presenta un notable dinamismo, encabezado por China, en paralelo con el propio desarrollo de sus economías.

Palabras clave: ferias comerciales, marketing, desarrollo económico, comercio exterior, infraestructura comercial.

Clasificación JEL: D12, F14, M31, M37.

\section{Introducción}

Ya existieron ferias en antiguas civilizaciones, como la griega o la romana, que fueron evolucionando a lo largo de los siglos, adaptándose a las necesidades económicas de cada momento. La mayoría de las principales ferias europeas tienen su origen en la expansión económica y la política territorial, religiosa y comercial empleada en la época carolingia (Carreras y Torra, 2004). La celebración de ferias en la Edad Media, especialmente a partir del siglo XII, ayuda a comprender cómo afectan las mismas al comercio y a la compraventa de productos variados y de diferente procedencia. En España se llegan a celebrar numerosas ferias en la Edad Media, en distintas localidades y regiones.

* Profesor en ESIC Business \& Marketing School (Campus Valencia). Profesor-consultor-especialista en ferias comerciales.

Versión de abril de 2016.
Por ejemplo, se contabilizan alrededor de cien concesiones de nuevas ferias a distintas poblaciones catalanas, dentro de la antigua Corona de Aragón, entre los años 1035 y 1443 (Carreras y Torra, 2004). Algunas ferias, en la Corona de Castilla, llegaron a alcanzar un gran reconocimiento, como las de Villalón, Medina de Rioseco y Medina del Campo. Pero la mayor parte de estas ferias desaparecieron con el paso del tiempo. A finales del siglo XIX y principios del xx comienzan a celebrarse ferias de nueva creación en diferentes ciudades europeas, como fue la de Valencia en el caso español, a partir de 1917 (Lluch, 1982), a la que sucederían otras, y que fueron, en primer lugar, de carácter multisectorial y dirigidas al consumidor, y derivarían en su mayoría, a partir de los años sesenta, en ferias especializadas o monográficas, similares a como son hoy en día. 
Las actuales manifestaciones feriales distan mucho de los antiguos mercados y ferias de la época, si bien su finalidad, en última instancia, sigue siendo la comercial principalmente. Pero a las ferias actuales se les asignan múltiples funciones: comunicación, promoción, ventas, relaciones, intercambio de información, investigación, fidelización de clientes, posicionamiento, distribución, formación, test de mercado y de producto, entre otras (Puchalt, 2001). De hecho, en las ferias coinciden, antes, durante y después de las mismas, casi todas las variables relacionadas con la comunicación empresarial (Munuera et al., 1993). Para Stevens (2005) las ferias son destacados medios de comunicación, pues combinan de forma única ventas y marketing, aprovechando las ventajas y oportunidades de ambas. Las ferias favorecen el desarrollo económico y facilitan el cumplimiento de los objetivos empresariales de las firmas expositoras, de los visitantes, de las organizaciones feriales y de otras empresas proveedoras. Muchos de los trabajos relativos a las ferias hacen alusión a las notables posibilidades que ofrecen para lograr contactos de calidad en un corto período de tiempo (Munuera et al., 1995; Puchalt, 2001; Jiménez et al., 2002; Mesonero, 2004). Suponen una excelente oportunidad para el contacto cara a cara con múltiples colectivos relacionados con la empresa que participa en la feria como expositora: además de los clientes actuales y potenciales, intermediarios actuales y futuros, proveedores, accionistas, empresas competidoras, directivos, empleados y colaboradores, Administración, estudiantes y la sociedad en general (Godar y O'Connor, 2001). Para los visitantes, ya sean profesionales o consumidores, las ferias comerciales permiten conocer, en tan solo unos días, la situación del sector, las últimas novedades y soluciones, la importancia de los expositores, las acciones de comunicación realizadas, los niveles de competencia, y los precios y condiciones, entre otros aspectos.
En definitiva, podemos definir las ferias comerciales como eventos, de unos pocos días de duración, habitualmente de celebración periódica, y con una función de marketing, en el que un determinado número de empresas de uno o más sectores económicos -expositores- participa en los mismos, para exponer sus productos o servicios y para ponerse en contacto con otras empresas clientes -reales o potenciales-, profesionales, prescriptores, o consumidores, que asisten a dichos eventos como visitantes $\mathrm{y}$, tanto unos como otros, fundamentalmente con fines comerciales, de investigación y para intercambiar información, ideas y opiniones (Puchalt, 2001).

El objetivo del presente trabajo es el de conocer la envergadura de la actividad ferial en Asia-Pacífico, sus características, el comportamiento y evolución de sus distintos parámetros en la última década y otros aspectos de interés. Para ello se analizan principalmente quince países de la zona. El directorio $\mathrm{m}+\mathrm{a}$, al que se alude un poco más adelante, permite ver que en otros países del área geográfica también se celebran ferias, aunque no presentan cifras significativas: Afganistán, Bangladesh, Camboya, Myanmar, Sri Lanka y Nueva Zelanda, entre otros.

\section{Panorama del sector ferial en Asia-Pacífico}

La asociación internacional $\mathrm{UFI}^{1}$, The Global Association of the Exhibition Industry, estima que actualmente se celebran unas 31.000 ferias al año en todo el mundo, que suponen una ocupación de 124 millones de metros cuadrados de superficie de exposición neta y en las que participan 4,4 millones de empresas expositoras y 260 millones de visitantes (UFI, 2014). Por otra parte, el conocido directorio y buscador ferial $m+a^{2}$ presenta $D$

\footnotetext{
${ }^{1}$ www.ufi.org

${ }^{2}$ www.expodatabase.com (consulta realizada en octubre de 2015)
} 


\begin{tabular}{|c|c|c|c|c|c|c|c|c|c|c|c|c|}
\hline \multirow{3}{*}{ Países } & \multicolumn{11}{|c|}{$\begin{array}{c}\text { CUADRO } 1 \\
\text { EVOLUCIÓN DEL PIB ANUAL EN PAÍSES DE ASIA-PACÍFICO EN 2004-2014 }\end{array}$} & \multirow{3}{*}{$\begin{array}{l}\text { Crecimiento } \\
\text { medio (\%) }\end{array}$} \\
\hline & \multicolumn{11}{|c|}{ Crecimiento del PIB (\%) } & \\
\hline & 2004 & 2005 & 2006 & 2007 & 2008 & 2009 & 2010 & 2011 & 2012 & 2013 & 2014 & \\
\hline China ${ }^{1} \ldots \ldots \ldots \ldots \ldots \ldots \ldots$ & 10,1 & 11,4 & 12,7 & 14,2 & 9,6 & 9,2 & 10,6 & 9,5 & 7,8 & 7,7 & 7,3 & 10,0 \\
\hline Japón............................. & 2,4 & 1,3 & 1,7 & 2,2 & $-1,0$ & $-5,5$ & 4,7 & $-0,5$ & 1,8 & 1,6 & $-0,1$ & 0,8 \\
\hline Corea del Sur ............. & 4,9 & 3,9 & 5,2 & 5,5 & 2,8 & 0,7 & 6,5 & 3,7 & 2,3 & 2,9 & 3,3 & 3,8 \\
\hline Hong Kong ................. & 8,7 & 7,4 & 7,0 & 6,5 & 2,1 & $-2,5$ & 6,8 & 4,8 & 1,7 & 3,1 & 2,5 & 4,4 \\
\hline 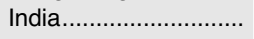 & 7,9 & 9,3 & 9,3 & 9,8 & 3,9 & 8,5 & 10,3 & 6,6 & 5,1 & 6,9 & 7,3 & 7,7 \\
\hline Australia ....................... & 4,1 & 3,2 & 3,0 & 3,8 & 3,7 & 1,8 & 2,0 & 2,4 & 3,6 & 2,4 & 2,5 & 3,0 \\
\hline Tailandia ...................... & 6,3 & 4,2 & 5,0 & 5,4 & 1,7 & $-0,7$ & 7,5 & 0,8 & 7,3 & 2,8 & 0,9 & 3,7 \\
\hline Singapur ........................ & 9,5 & 7,5 & 8,9 & 9,1 & 1,8 & $-0,6$ & 15,2 & 6,2 & 3,4 & 4,4 & 2,9 & 6,2 \\
\hline Indonesia ..................... & 5,0 & 5,7 & 5,5 & 6,3 & 6,0 & 4,6 & 6,2 & 6,2 & 6,0 & 5,6 & 5,0 & 5,6 \\
\hline Filipinas ......................... & 6,7 & 4,8 & 5,2 & 6,6 & 4,2 & 1,1 & 7,6 & 2,6 & $-1,4$ & $-1,1$ & $-0,4$ & 3,3 \\
\hline Malasia ........................... & 6,8 & 5,3 & 5,6 & 6,3 & 4,8 & $-1,5$ & 7,4 & 5,3 & 5,5 & 4,7 & 6 & 5,1 \\
\hline Pakistán......................... & 7,4 & 7,7 & 6,2 & 4,8 & 1,7 & 2,8 & 1,6 & 2,7 & 3,5 & 4,4 & 4,7 & 4,3 \\
\hline Vietnam ....................... & 7,5 & 7,5 & 7,0 & 7,1 & 5,7 & 5,4 & 6,4 & 6,2 & 5,2 & 5,4 & 6,0 & 6,3 \\
\hline Macao........................ & 26,9 & 8,6 & 14,4 & 14,3 & 3,4 & 1,7 & 27,5 & 21,3 & 9,2 & 10,7 & $-0,4$ & 12,5 \\
\hline Crecim. medio (\%) .... & 8,2 & 6,3 & 6,9 & 7,3 & 3,6 & 1,8 & 8,6 & 5,6 & 4,4 & 4,4 & 3,4 & 5,5 \\
\hline
\end{tabular}

datos de ferias que se celebran en 1.482 ciudades de 126 países. Otro directorio y buscador, EventsEye ${ }^{3}$, contiene eventos que tienen lugar en 1.016 ciudades de 134 países. Se trata por tanto de una actividad muy extendida y habitual en un gran número de países.

Europa representaba más de la mitad del mercado mundial de ferias en el año 2004, y actualmente dispone de la mayor capacidad de exposición y reúne los mayores recintos feriales y a los principales organizadores, sobre los que recae el mayor porcentaje de la actividad (Puchalt, 2008). EEUU y Canadá registran asimismo cifras muy relevantes. Incluyendo los más de 5.500 eventos de pequeñas dimensiones, entre 280 y $930 \mathrm{~m}^{2}$, se estiman al año más de 14.000 certámenes (Puchalt y Munuera, 2008). Por otra parte, como iremos viendo, la industria ferial en los países de AsiaPacífico muestra un notable dinamismo en toda la última década analizada, liderado especialmente por China.

El Cuadro 1 muestra la evolución económica de Asia-Pacífico desde 2004 a 2014, a través del crecimiento anual del producto interior bruto en diferentes países, con datos procedentes del Banco Mundial ${ }^{4}$. El crecimiento medio anual

\footnotetext{
${ }^{3}$ www.eventseye.com (consulta realizada en octubre de 2015).

${ }^{4}$ www.bancomundial.org
}

conjunto es del 5,5 por 100. Destaca el crecimiento medio del PIB de: Macao (12,5 por 100), China (10), India $(7,7)$, Vietnam $(6,3)$, Singapur $(6,2)$ e Indonesia $(5,6)$. Y también es de señalar el escaso crecimiento medio anual de Japón, del 0,8 por 100.

La UFI (2014) estima que la cuota de AsiaPacífico sobre el total mundial, en términos de ocupación ferial, pasó del 14,9 por 100 en 2008 al 17,4 por 100 en 2012, como muestra el Cuadro 2, es decir, registró un aumento de la cuota del 9,1 por 100, mientras Europa y Norteamérica -EEUU y Canadá- disminuyeron su participación en dicho periodo, un 12,5 y un 8,6 por 100 respectivamente, pasando del 40 por 100 de cuota al 37,3 por 100 en el caso de Europa, $y$ del 39,5 al 38,4 por 100 en el caso de Norteamérica. La UFI (2014), estima igualmente que las ferias de China en 2012 totalizaron 13,7 millones de $\mathrm{m}^{2}$ de espacio alquilado. Estos datos relativos a Asia-Pacífico contrastan con los que presentan las investigaciones de BSG (Business Strategies Group) a lo largo de la década, y recogidos en este trabajo, pero la propia UFI (2014) apunta que estos últimos vienen a representar realmente el 75 por 100 de la actividad en la región en términos de espacio alquilado, porcentaje que podría extrapolarse a otros datos de este artículo. 


\begin{tabular}{|c|c|c|c|c|c|c|c|c|c|}
\hline \multicolumn{10}{|c|}{$\begin{array}{c}\text { CUADRO } 2 \\
\text { EVOLUCIÓN DE LA OCUPACIÓN FERIAL POR ZONAS GEOGRÁFICAS }\end{array}$} \\
\hline \multirow{2}{*}{ Zonas geográficas } & \multicolumn{2}{|c|}{2008} & \multicolumn{2}{|c|}{2010} & \multicolumn{2}{|c|}{2012} & \multirow{2}{*}{$\begin{array}{c}\% \\
\text { Variación } \\
2010 / 08\end{array}$} & \multirow{2}{*}{$\begin{array}{c}\% \\
\text { Variación } \\
\text { 2012/10 }\end{array}$} & \multirow{2}{*}{$\begin{array}{c}\% \\
\text { Variación } \\
2012 / 08\end{array}$} \\
\hline & $\begin{array}{l}\text { Ocupación } \\
\left.\text { (mill. } \mathbf{m}^{2}\right)\end{array}$ & $\%$ & $\begin{array}{l}\text { Ocupación } \\
\left(\text { mill. } \mathbf{m}^{2}\right)\end{array}$ & $\%$ & $\begin{array}{l}\text { Ocupación } \\
\left(\text { mill. } \mathrm{m}^{2}\right)\end{array}$ & $\%$ & & & \\
\hline 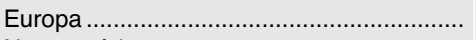 & 53,0 & 40,0 & 47,7 & 39,2 & 46,4 & 37,3 & -10 & $-2,7$ & -12.5 \\
\hline 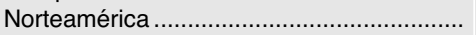 & 52,3 & 39,5 & 45,6 & 37,4 & 47,8 & 38,4 & $-12,8$ & 2,8 & $-8,6$ \\
\hline 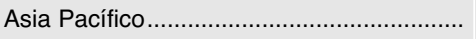 & 19,8 & 14,9 & 20,6 & 16,9 & 21,6 & 17,4 & 4,0 & 4,9 & 9,1 \\
\hline 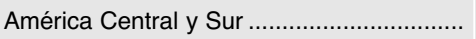 & 4,0 & 3,0 & 4,4 & 3,6 & 5,1 & 4,1 & 10,0 & 15,9 & 27,5 \\
\hline 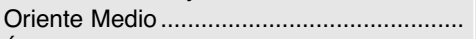 & 2,4 & 1,8 & 2,5 & 2,0 & 2,6 & 2,1 & 4,2 & 4,0 & 8,3 \\
\hline África & 1,0 & 0,8 & 1,0 & 0,8 & 1,0 & 0,8 & 0,0 & 0,0 & 0,0 \\
\hline 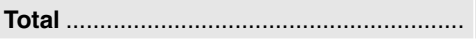 & 132,5 & 100,0 & 121,8 & 100,0 & 124,5 & 100,0 & $-8,1$ & 100,0 & $-6,8$ \\
\hline
\end{tabular}

\begin{tabular}{|c|c|c|c|c|c|c|c|c|c|c|c|c|c|c|}
\hline \multirow{3}{*}{ Países } & \multicolumn{13}{|c|}{$\begin{array}{l}\text { CUADRO } 3 \\
\text { IS CELEBRADAS EN ASIA-PACÍFICO EN 2004-2014 }\end{array}$} & \multirow{3}{*}{$\begin{array}{c}\text { Crecimiento } \\
\text { medio anual } \\
\text { (\%) }\end{array}$} \\
\hline & \multicolumn{11}{|c|}{ Número de ferias } & \multirow{2}{*}{$\begin{array}{l}\text { Porcentaje } \\
\text { s/total } 2014\end{array}$} & \multirow{2}{*}{$\begin{array}{l}\text { Variación } \\
14 / 04^{1}(\%)\end{array}$} & \\
\hline & 2004 & 2005 & 2006 & 2007 & 2008 & 2009 & 2010 & 2011 & 2012 & 2013 & 2014 & & & \\
\hline 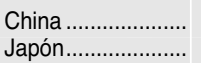 & $\begin{array}{l}555 \\
476\end{array}$ & $\begin{array}{l}567 \\
473\end{array}$ & $\begin{array}{l}587 \\
475\end{array}$ & $\begin{array}{l}456 \\
362\end{array}$ & $\begin{array}{l}493 \\
360\end{array}$ & $\begin{array}{l}514 \\
326\end{array}$ & $\begin{array}{l}517 \\
329\end{array}$ & $\begin{array}{l}532 \\
323\end{array}$ & $\begin{array}{l}542 \\
332\end{array}$ & $\begin{array}{l}565 \\
329\end{array}$ & $\begin{array}{l}619 \\
338\end{array}$ & $\begin{array}{l}29,0 \\
15,9\end{array}$ & $\begin{array}{r}11,5 \\
-29,0\end{array}$ & $\begin{array}{r}1,5 \\
-3,0\end{array}$ \\
\hline Corea del Sur ........ & 141 & 139 & 140 & 151 & 146 & 154 & 147 & 152 & 156 & 160 & 158 & 7,4 & 12,1 & 1,2 \\
\hline Hong Kong ............ & 56 & 55 & 82 & 84 & 85 & 88 & 98 & 101 & 113 & 109 & 95 & 4,5 & 69,6 & 6,4 \\
\hline India........................ & 130 & 130 & 158 & 113 & 131 & 112 & 127 & 134 & 138 & 145 & 162 & 7,6 & 24,6 & 3,3 \\
\hline Australia.................. & nd & nd & 151 & 168 & 165 & 166 & 166 & 171 & 176 & 179 & 182 & 8,5 & 20,5 & 2,8 \\
\hline Taiwán ..................... & 47 & 58 & 60 & 46 & 62 & 63 & 74 & 80 & 74 & 89 & 102 & 4,8 & 117,0 & 9,3 \\
\hline Tailandia ................ & 65 & 56 & 69 & 63 & 71 & 75 & 71 & 77 & 83 & 77 & 88 & 4,1 & 35,4 & 3,7 \\
\hline Singapur ................... & 53 & 52 & 59 & 52 & 69 & 74 & 80 & 97 & 86 & 93 & 88 & 4,1 & 66,0 & 6,0 \\
\hline Indonesia ................ & 56 & 55 & 54 & 48 & 41 & 43 & 43 & 47 & 49 & 51 & 63 & 3,0 & 12,5 & 1,7 \\
\hline Filipinas .................... & 62 & 62 & 59 & 58 & 35 & 36 & 38 & 41 & 43 & 44 & 46 & 2,2 & $-25,8$ & $-1,8$ \\
\hline Malasia ..................... & 41 & 54 & 57 & 53 & 47 & 43 & 49 & 57 & 64 & 77 & 78 & 3,7 & 90,2 & 7,5 \\
\hline Pakistán .................. & 17 & 17 & 32 & 21 & 25 & 26 & 27 & 28 & 28 & 29 & 29 & 1,4 & 70,6 & 8,8 \\
\hline Vietnam .................. & 48 & 41 & 56 & 47 & 47 & 47 & 50 & 51 & 55 & 57 & 58 & 2,7 & 20,8 & 2,8 \\
\hline Macao ...................... & nd & nd & nd & 10 & 16 & 15 & 17 & 14 & 9 & 9 & 26 & 1,2 & 160,0 & 28,9 \\
\hline Total .......................... & 1.747 & 1.759 & 2.039 & 1.732 & 1.793 & 1.782 & 1.833 & 1.905 & 1.948 & 2.013 & 2.132 & 100,0 & 22,0 & 2,3 \\
\hline
\end{tabular}

En el Cuadro 3 puede observarse la evolución en el número de ferias desde 2004 a 2014 en los 15 países analizados. En ese periodo, el incremento conjunto ha sido del 22 por 100 , alcanzando la cifra máxima, 2.132 eventos, en el último año. El crecimiento anual medio se sitúa en el 2,3 por 100. El comportamiento ha sido desigual para los diferentes países, registrando descensos únicamente en el caso de Japón, un 29 por 100, es decir 138 ferias menos en 2014 que en 2004, y Filipinas, un 25,8 por 100 (-16 ferias). Los incrementos más significativos los presentan: Macao (160 por 100, desde 2007), Taiwán (117), Malasia $(90,2)$, Pakistán $(70,6)$, Hong Kong $(69,6)$ y Singapur (66).
Las investigaciones relativas a toda la década analizada, como muestra el Cuadro 4, revelan que la ocupación del espacio neto en las ferias de Asia-Pacífico pasó de 8.188.250 $\mathrm{m}^{2}$ en 2004 a $18.641 .750 \mathrm{~m}^{2}$ en 2014 , lo que representa un crecimiento del 127,7 por 100 , es decir un porcentaje cinco veces mayor al producido con relación al número de ferias celebradas. Además, dicho crecimiento se produce año tras año sin excepción. El crecimiento medio anual en materia de ocupación, para el conjunto de países, fue del 8,8 por 100 , frente al 2,3 por 100 mencionado anteriormente, relativo a las ferias celebradas (UFI-BSG, 2005-2015). Del total de las ferias registradas en 2014 , corresponde a China el 29 por 100, es decir $619, D$ 


\begin{tabular}{|c|c|c|c|c|c|c|c|}
\hline \multirow{3}{*}{ Países } & LUCIÓN DE & IPERFICIE & $\begin{array}{r}\text { CL } \\
\text { ADA EN LAS }\end{array}$ & $\begin{array}{l}04 \\
\text { AS CELEBR }\end{array}$ & EN ASIA-P & CO EN 2004- & \\
\hline & \multicolumn{7}{|c|}{ Superficie neta $\left(\mathrm{m}^{2}\right)$} \\
\hline & 2004 & 2005 & 2006 & 2007 & 2008 & 2009 & 2010 \\
\hline China ...................... & 3.551 .500 & $\begin{array}{l}4.174 .000 \\
2.156750\end{array}$ & $\begin{array}{l}5.088 .500 \\
2174.250\end{array}$ & $\begin{array}{l}6.716 .250 \\
2.196 .750\end{array}$ & 7.647 .500 & 8.163 .250 & $\begin{array}{l}8.517 .500 \\
1.928 .250\end{array}$ \\
\hline Corea del Sur ... & 509.000 & $\begin{array}{r}2.156 .150 \\
515.250\end{array}$ & $\begin{array}{r}2.1 / 4.250 \\
528.000\end{array}$ & $\begin{array}{r}2.196 .150 \\
694.500\end{array}$ & $\begin{array}{r}2.056 .150 \\
745.750\end{array}$ & $\begin{array}{r}1.91 / .500 \\
774.750\end{array}$ & $\begin{array}{r}1.928 .250 \\
802.750\end{array}$ \\
\hline Hong Kong......... & 501.000 & 523.250 & 776.250 & 803.750 & 822.500 & 787.000 & 870.000 \\
\hline India ................... & 427.500 & 380.750 & 526.000 & 648.250 & 693.500 & 703.500 & 763.750 \\
\hline Australia.............. & nd & nd & 410.250 & 445.250 & 510.250 & 519.500 & 528.000 \\
\hline Taiwán................ & 301.250 & 341.000 & 409.750 & 365.000 & 458.500 & 487.250 & 552.000 \\
\hline Tailandia............. & 191.750 & 274.250 & 380.500 & 373.750 & 448.750 & 466.500 & 432.500 \\
\hline Singapur ............ & 179.250 & 182.000 & 201.500 & 206.250 & 229.250 & 241.250 & 250.000 \\
\hline Indonesia ........... & 123.250 & 171.000 & 169.500 & 186.500 & 161.000 & 163.250 & 167.750 \\
\hline Filipinas.............. & 120.250 & 124.250 & 114.000 & 92.750 & 80.500 & 82.000 & 128.250 \\
\hline Malasia .............. & 110.250 & 165.500 & 246.000 & 247.250 & 223.250 & 233.750 & 265.000 \\
\hline Pakistán ............. & 38.000 & 41.250 & 61.500 & 67.000 & 64.250 & 64.750 & 66.750 \\
\hline Vietnam................ & 28.250 & 63.500 & 109.000 & 113.500 & 140.750 & 141.250 & 141.500 \\
\hline Macao ................. & nd & nd & nd & 39.250 & 66.250 & 97.750 & 125.000 \\
\hline Total .................. & 8.188 .250 & 9.112 .750 & 11.195 .000 & 13.196 .000 & 14.348 .750 & 14.903 .250 & 15.539 .000 \\
\hline
\end{tabular}

\begin{tabular}{|c|c|c|c|c|c|c|c|}
\hline \multicolumn{8}{|c|}{$\begin{array}{c}\text { CUADRO } 4 \text { (continuación) } \\
\text { EVOLUCIÓN DE LA SUPERFICIE OCUPADA EN LAS FERIAS CELEBF }\end{array}$} \\
\hline Países & 2011 & 2012 & 2013 & 2014 & $\begin{array}{l}\text { Porcentaje } \\
\text { s/total } 2014\end{array}$ & $\begin{array}{c}\text { Variación } \\
2014 / 2004 \\
(\%)^{1}\end{array}$ & $\begin{array}{c}\text { Crecimiento } \\
\text { medio } \\
\text { anual (\%) }\end{array}$ \\
\hline China .................. & 8.733 .750 & 8.996 .000 & 9.719 .750 & 10.443 .000 & 56 & 194 & 11,7 \\
\hline Japón ................... & 1.873 .000 & 1.932 .750 & 1.977 .000 & 2.026 .750 & 10,9 & $-3,8$ & $-0,3$ \\
\hline Corea del Sur ... & 820.250 & 826.750 & 854.500 & 924.750 & 5,0 & 81,7 & 6,5 \\
\hline Hong Kong......... & 880.000 & 876.500 & 906.000 & 934.750 & 5,0 & 86,6 & 7,2 \\
\hline India ........................ & 789.000 & 810.750 & 854.750 & 920.000 & 5,0 & 115,2 & 8,7 \\
\hline Australia............. & 522.750 & 536.750 & 556.250 & 574.000 & 3,1 & 39,9 & 4,4 \\
\hline Taiwán................. & 619.250 & 629.250 & 716.250 & 779.250 & 4,2 & 158,7 & 10,4 \\
\hline Tailandia.............. & 462.500 & 464.250 & 506.250 & 550.000 & 3,0 & 186,8 & 12,2 \\
\hline Singapur ............. & 286.500 & 296.000 & 329.250 & 332.500 & 1,8 & 85,5 & 6,5 \\
\hline Indonesia ............ & 178.000 & 189.750 & 203.000 & 221.750 & 1,2 & 79,9 & 6,7 \\
\hline Filipinas............... & 139.500 & 145.000 & 151.250 & 164.500 & 0,9 & 36,8 & 4,7 \\
\hline Malasia .............. & 302.500 & 308.250 & 300.000 & 321.000 & 1,7 & 191,2 & 12,8 \\
\hline Pakistán ............. & 70.750 & 72.500 & 77.000 & 81.750 & 0,4 & 115,1 & 8,7 \\
\hline Vietnam............... & 143.250 & 150.250 & 158.750 & 170.250 & 0,9 & 502,7 & 24,4 \\
\hline Macao .................. & 84.500 & 72.500 & 72.500 & 197.500 & 1,1 & 403,2 & 38,6 \\
\hline Total ................... & 15.905 .500 & 16.307 .250 & 17.382 .500 & 18.641 .750 & 100,0 & 127,7 & 8,8 \\
\hline
\end{tabular}

y el 56 por 100 de la superficie total, $10.443 .000 \mathrm{~m}^{2}$. A Japón, el segundo país con mayor actividad, corresponde un 15,9 por 100 de las ferias, 338, y un 11 por 100 de la superficie total. Australia es el tercer país en número de ferias, 182, es decir el 8,2 por 100 de las ferias totales, y el 3,1 por 100 de la superficie ocupada global.

Los países con incrementos iguales o superiores a la media entre 2004 y 2014, en materia de superficie ocupada, son: Vietnam $(502,7$ por 100), Macao $(403,2)$, Malasia $(191,2)$,
Tailandia $(186,8)$, Taiwán $(158,7)$, India $(115,2)$ y Paquistán (115,1). Al comparar sus datos de ocupación de ambos años, Japón es el único país que registra una disminución, del 3,8 por 100 , frente a la del 29 por 100 en el número de ferias, si bien muestra crecimientos sucesivos en dicho parámetro desde 2004 a 2007 y desde 2011 a 2014. La ocupación conjunta de los cinco primeros países por dicho concepto, China, Japón, Corea, Hong Kong e India, representa casi el 82 por 100 del total, porcentaje que $\triangleright$ 


PRINCIPALES ORGANIZADORES FERIALES EN ASIA PACíFICO
Organizadores

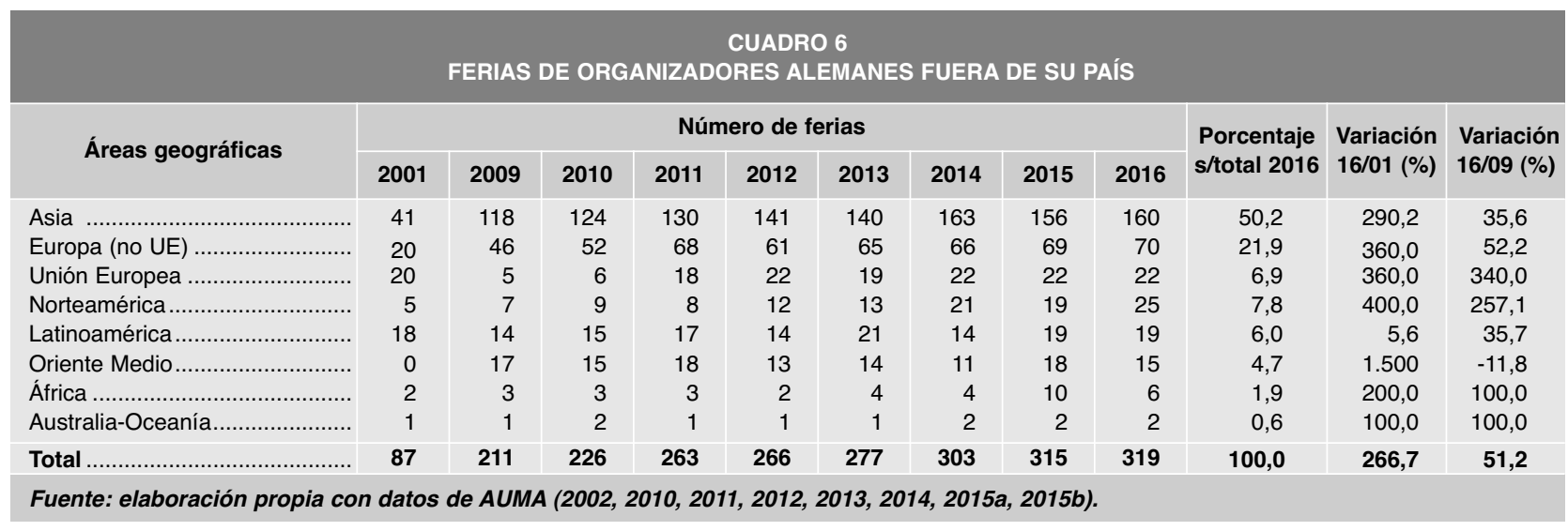

alcanza el 89,2 añadiendo los datos de superficie de Taiwán y de Australia. Además, China es el segundo país del mundo en materia de ocupación ferial, por delante de Alemania, y sólo superado por EEUU (UFI, 2014).

\section{Organizadores de ferias en la región}

Los principales organizadores que operan en Asia-Pacífico, tomando como referencia la superficie ocupada por sus ferias, aparecen detallados en el Cuadro 5, según la información procedente de varias ediciones de UFI-BSG (2005-2012). Entre ellas cabe destacar la presencia de algunos de los mayores operadores mundiales: Reed Exhibitions, UBM, Messe Frankfurt y Messe Köln, todos ellos europeos, y con oficinas en Asia.
En materia de ferias, es relevante el protagonismo de los organizadores de países ajenos al área objeto de estudio, fundamentalmente de Europa. En el caso de las organizaciones alemanas, este tipo de actividades es creciente año tras año, como puede observarse en el Cuadro 6. De acuerdo con la asociación de ferias alemanas AUMA $^{5}$ (2015a), en 2014, las 21 entidades de Alemania miembros de dicha asociación y de FAMA ${ }^{6}$, organizaron 303 ferias en el exterior del país, basadas en certámenes celebrados con éxito en su sede habitual. De las 303 ferias, 163 tuvieron lugar en Asia (53,8 por 100) y 2 en Australia (0,7 por 100). El resto, 66 , corresponden a países europeos no comunitarios (21,8 por 100); 22 a países de la $\triangleright$

\footnotetext{
${ }^{5}$ www.auma.de (Ausstellungs- und Messe-Ausschuss der Deutschen Wirtschaft e.V.).

${ }^{6}$ www.fama.de (Fachverband Messen und Ausstellungen e.V.).
} 
Unión Europea (7,3 por 100); 21 a Norteamérica $(6,9$ por 100$) ; 14$ a Latinoamérica $(4,6$ por 100); 11 a Oriente Medio (3,6 por 100); y 4 a África (1,3 por 100). Se trata de ferias que cubren muy diferentes sectores: maquinaria, industria textil, alimentación, agricultura y actividad forestal, tecnología médica, construcción, etcétera. La ocupación neta total de las ferias organizadas en el exterior fue de 3,7 millones de $\mathrm{m}^{2}$, el número de expositores 124.000 , y el número de visitantes se situó en 7,3 millones (AUMA, 2015a).

En 2015 se celebraron 315 de estas ferias fuera de Alemania, y la previsión para 2016 es de 319 , en 37 países diferentes, organizadas por 18 miembros de AUMA, destacando nuevamente Asia, con 160 eventos, seguida de la Europa no comunitaria con 70 ferias, Norteamérica 25, países de la Unión Europea 22, Latinoamérica 19, Oriente Medio 15, África 6 y Australia/Oceanía 2 (AUMA (2015b).

Atendiendo a los datos que muestra el Cuadro 6, la mitad de las ferias organizadas por entidades alemanas en el exterior son llevadas a cabo en Asia-Pacífico, lo que demuestra el interés de los organizadores por dichos mercados, así como el de las empresas que, como expositoras, invierten y confían en el instrumento ferial en los países y regiones mencionados. En 2016 el foco principal de la actividad ferial alemana en el exterior se centra en China, India, Rusia, Turquía y EEUU, suponiendo estos cinco países dos terceras partes de las 319 ferias previstas. Concretamente, las ferias que se celebran en 2016 en AsiaPacífico se concentran principalmente en China, en las ciudades de Shanghái, Guangzhou, Beijing, Chengdu, Foshan, Nanjing, Shenzhen, Wuhan y Yiwu -principalmente en las tres primeras-, así como en Hong Kong y Macao. En India, las ferias previstas tienen lugar en Mumbai, Nueva Delhi, Ahmedabad, Bangalore, Chennai, Coimbatore, Dhansura, Gandhinagar, Gurgaon/ Delhi, Hyderabad y Karnal, en especial en las dos primeras. En Japón, en Tokio, Osaka y Fukuoka; en Indonesia, Yakarta; en Tailandia, Bangkok; en Vietnam, Ho Chi Minh; en Australia, Melbourne y Sídney y otros países en los que organizan ferias los operadores alemanes son Singapur y Taiwán (AUMA, 2015b). Por tanto, un porcentaje importante de las ferias celebradas en Asia-Pacífico corresponde a organizadores alemanes.

\section{Análisis sectorial}

Si analizamos el comportamiento de las ferias desde el punto de vista sectorial, en 2014, el sector de ingeniería y productos industriales, con 2,12 millones de $\mathrm{m}^{2}$ de espacio ocupado, se mantiene como el más representado. El segundo es el de productos terminados en general, con una ocupación de 1,91 millones de $\mathrm{m}^{2}$. El sector del mueble, el tercero más representado, totaliza 1,78 millones de $\mathrm{m}^{2}$. Otros seis sectores registran ocupaciones por encima del millón de $\mathrm{m}^{2}$ : electrónica, alimentación y bebidas, textiles, ocio, construcción y automoción (UFI-BSG, 2015). Como muestra el Cuadro 7, el peso de los sectores se ha mantenido bastante invariable desde las primeras investigaciones por parte de BSG en 2005. Solo las categorías correspondientes a productos industriales y productos terminados en general superaron el 10 por 100 del espacio ocupado en 2014. El sector del mueble e interiorismo estuvo ligeramente por debajo del 10 por 100. En un segundo bloque podrían situarse otros siete sectores que alcanzaron un porcentaje entre el 5 y el 10 por 100: electrónica y componentes, que ha pasado del 5 al 7 por 100; textiles, ropa y moda; alimentación, bebidas y hospitality; ocio, hobby y entretenimiento; automóviles y motocicletas; construcción e infraestructuras, que ha pasado del 3 al 6 por 100; y productos premium, hogar, regalos y juguetes, que ha disminuido su presencia, pasando, de suponer el 9 por 100 en 2004, $\triangleright$ 


\begin{tabular}{|c|c|c|c|c|c|c|c|}
\hline \multicolumn{8}{|c|}{$\begin{array}{l}\text { CUADRO } 7 \\
\text { EVOLUCIÓN DE LOS SECTORES PRESENTES EN LAS FERIAS CELEBRADAS EN ASIA-PACÍFICO } \\
\text { (En términos porcentuales) }\end{array}$} \\
\hline Sectores & $\begin{array}{c}2004 \\
(\%)\end{array}$ & $\begin{array}{c}2005 \\
(\%)\end{array}$ & $\begin{array}{c}2006 \\
(\%)\end{array}$ & - & $\begin{array}{c}2012 \\
(\%)\end{array}$ & $\begin{array}{c}2013 \\
(\%)\end{array}$ & $\begin{array}{c}2014 \\
(\%)\end{array}$ \\
\hline Ingeniería, industria, manufacturas, maquinaria, instrumentos.................. & 10 & 11 & 11 & - & 10 & 10 & 11 \\
\hline General (productos terminados) & 10 & 10 & 8 & - & 10 & 10 & 10 \\
\hline 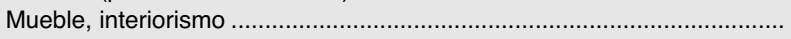 & 9 & 9 & 12 & - & 10 & 10 & 10 \\
\hline 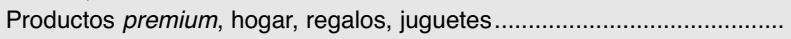 & 9 & 7 & 8 & - & 6 & 5 & 5 \\
\hline Textiles, ropa, moda & 7 & 8 & 8 & - & 6 & 6 & 6 \\
\hline Alimentación, bebidas, hospitality ................. & 7 & 6 & 6 & - & 6 & 6 & 6 \\
\hline TI y telecomunicaciones .................................... & 6 & 6 & 5 & - & 4 & 4 & 4 \\
\hline 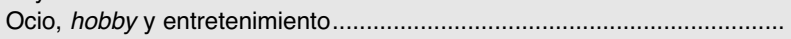 & 5 & 5 & 6 & - & 6 & 6 & 6 \\
\hline 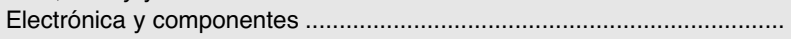 & 5 & 6 & 6 & - & 6 & 6 & 7 \\
\hline 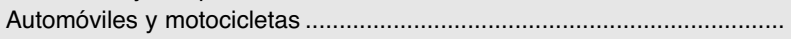 & 5 & 5 & 4 & - & 5 & 5 & 6 \\
\hline 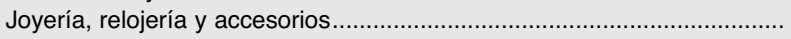 & 4 & 3 & 4 & - & 3 & 3 & 3 \\
\hline Salud y equipo médico & 3 & 5 & 4 & - & 4 & 4 & 4 \\
\hline 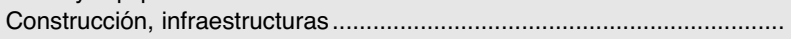 & 3 & 4 & 5 & - & 6 & 6 & 6 \\
\hline 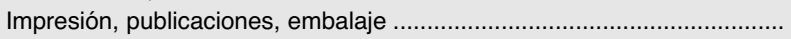 & 4 & 2 & 3 & - & 3 & 3 & 3 \\
\hline 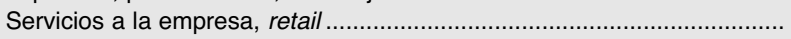 & 2 & 2 & 2 & - & 2 & 2 & 2 \\
\hline  & 2 & 2 & 1 & - & - & - & - \\
\hline 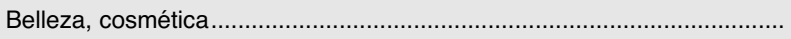 & 1 & 2 & 2 & - & 2 & 2 & 2 \\
\hline Viajes & 1 & 1 & 1 & - & - & - & - \\
\hline Agricultura, silvicultura, pesca & 1 & - & - & - & 1 & 1 & - \\
\hline  & - & 1 & 1 & - & 2 & 2 & 2 \\
\hline Transporte, logística, marítimo & - & 1 & 1 & - & - & - & 1 \\
\hline 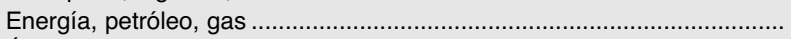 & - & - & - & - & 2 & 2 & 2 \\
\hline 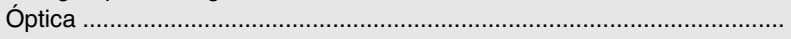 & - & - & - & - & 1 & 1 & 1 \\
\hline Otros & 7 & 4 & 3 & - & 4 & 4 & 4 \\
\hline
\end{tabular}

Los sectores con pequeña representación aparecen agrupados en otros. Los años centrales de la serie no están disponibles en las fuentes consultadas. Los totales pueden sumar más o menos que 100 por los redondeos en los porcentajes individuales.

Fuente: elaboración propia con datos de UFI-BSG (2005, 2006, 2007, 2013, 2014, 2015).

\begin{tabular}{|c|c|c|c|}
\hline \multicolumn{4}{|c|}{$\begin{array}{c}\text { CUADRO } 8 \\
\text { SECTORES PRESENTES EN LAS FERIAS DE ASIA-PACÍFICO EN } 2012\end{array}$} \\
\hline Sectores & Ferias & $\begin{array}{l}\text { Ocupación } \\
\left.\text { (mill. } \mathbf{m}^{2}\right)\end{array}$ & $\begin{array}{l}\text { Tamaño medio } \\
\text { por feria }\left(\mathrm{m}^{2}\right)\end{array}$ \\
\hline Construcción, hogar y reparación & 181 & 2,6 & 14.370 \\
\hline 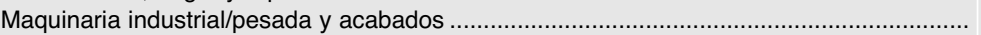 & 346 & 2,3 & 6.777 \\
\hline Servicios discrecionales al consumidor, educación y artículos deportivos / Viajes / Ocio.... & 277 & 2,3 & 8.348 \\
\hline Agricultura / Forestal / Pesca y energía / Petróleo / Gas / Química ....................................... & 107 & 0,6 & 5.460 \\
\hline  & 174 & 1 & 5.662 \\
\hline 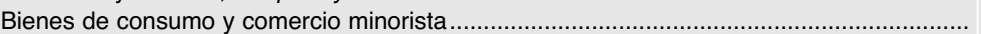 & 190 & 3,1 & 16.447 \\
\hline Transporte & 130 & 1,1 & 8.154 \\
\hline 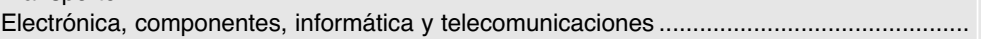 & 204 & 1,7 & 8.398 \\
\hline Atención médica y sanitaria & 134 & 0,9 & 6.343 \\
\hline 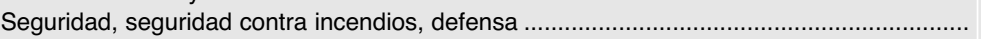 & 67 & 0,3 & 4.795 \\
\hline 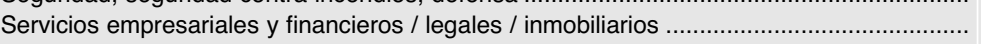 & 95 & 0,4 & 4.316 \\
\hline Total & 1.905 & 16,3 & 8.560 \\
\hline
\end{tabular}

a representar el 5 por 100 en 2014. Los 13 sectores restantes estarían por debajo del 5 por 100 respecto al total. De estos, el de tecnologías de la información y telecomunicaciones, pasa del 6 al 4 por 100 entre 2004 y 2014.

Adicionalmente, el Cuadro 8 recoge los datos de la UFI (2014) relativos al número de ferias celebradas, al espacio alquilado y al tamaño medio por feria en cada uno de los sectores, con datos pertenecientes a 2012. Por número de ferias, sobresalen los sectores de maquinaria industrial, con 346; servicios al consumidor, educación, deportes, viajes y ocio, con 277 ; y electrónica, informática y telecomunicaciones, con 204. En cuanto a la superficie ocupada, destacan los sectores de: bienes de consumo; construcción y hogar; maquinaria industria y servicios al consumidor, con más de 2 millones de $\mathrm{m}^{2}$ cada uno.

Entre las ferias organizadas por operadores alemanes en Asia, a las que se aludía en el $D$ 
apartado anterior, las cuatro con mayor número de expositores en 2014 tuvieron lugar en Shanghái. Automechanika Shanghai (industria del automóvil) reunió a 5.036 expositores; la edición de otoño de Intertextile Shanghai Apparel Fabrics (industria textil) alcanzó 3.844 expositores; Bauma China (construcción) tuvo 3.098 expositores y CHINAPLAS (plástico y caucho) 3.068. La quinta feria fue Guangzhou International Lighting Exhibition (iluminación), en Cantón, con 2.621 expositores, y la siguiente fue CIHS, China International Hardware Show (herramientas y maquinaria), también en Shanghái, con 2.610 expositores (AUMA, 2015a). Las tres ferias con mayor número de visitantes en 2014 fueron: Auto China (850.000 visitantes), CDMS, Chengdu Motor Show (674.500 visitantes) y Wuhan Motor Show (452.000 visitantes), todas del automóvil. Después de estas tres ferias dirigidas al público final, la siguiente por número de visitantes fue Bauma China, la feria de la construcción, con 189.732 visitantes. Todas ellas son cifras muy elevadas que permiten hacerse una idea de su gran envergadura.

Las ferias celebradas en China ese mismo año suponen el 30 por 100 del calendario que AUMA denomina GTQ (German Trade Fair Quality Abroad), que asciende a 90 ferias y el 56 por 100 de la superficie neta total, unos 2 millones de $\mathrm{m}^{2}$, así como el 50 por 100 de los expositores y el 63 por 100 de los visitantes. Otro país con un importante número de ferias en 2014, con la etiqueta GTQ, fue India, con 45 ferias, el 15 por 100 del total, si bien ello supuso solamente el 4 por 100 de la superficie ocupada, cerca de $160.000 \mathrm{~m}^{2}$, cerca del 5 por 100 de los visitantes y alrededor del 6 por 100 de los expositores.

\section{Ingresos estimados}

El Cuadro 9 muestra la evolución detallada de los ingresos estimados que genera la actividad ferial para los organizadores y recintos feriales en los distintos países, en dólares, producidos durante la década analizada.

Los ingresos producidos en la década han crecido cerca de un 150 por 100 para el conjunto de países de Asia-Pacífico, pasando de 1.885 millones de dólares en 2004 (sin tener en cuenta Australia y Macao, cuyos datos todavía no aparecen en la serie) a cerca de 4.707 millones de dólares en 2014. El crecimiento es superior al de la superficie ocupada, del 127,7 por 100 (Cuadro 4). Dicho crecimiento en los ingresos se produce todos los años de la serie, salvo en 2009, si bien, no es uniforme para todos los países. El crecimiento medio anual es del 11,1 por 100. En términos relativos, destacan: Vietnam (509,5 por 100), Macao $(356,3)$ entre 2007 y 2014, Tailandia $(331,1)$, Malasia $(287,3)$, Taiwán $(193,3)$, India $(192,3)$ y China $(171,4)$. Por el contrario, Filipinas es el único país que registra un crecimiento muy leve, de tan solo un 5 por 100 , país al que le sigue Japón con un crecimiento del 61,9 por 100 , en contraste con su comportamiento negativo neto en materia de superficie $(-3,8$ por 100$)$ y en el número de ferias (-29 por 100). Como ocurre con el resto de parámetros, la actividad ferial de China reúne el mayor porcentaje de ingresos en 2014, el 35,9 por 100 del total (33 por 100 en 2004), con 1.691 millones de dólares, aunque supone el 56 por 100 de la superficie global y el 29 por 100 de las ferias. El segundo país por ingresos, Japón, con 961 millones de dólares en 2014, representa un 20,4 por 100 del total (31,5 por 100 en 2004), mientras que supone un 10,9 por 100 de la superficie y un 15,9 por 100 de las ferias totales. El tercero de los países es Hong Kong, con 414,5 millones de dólares en 2014, que suponen el 8,8 por 100 (10,1 en 2004), frente al 5 por 100 de la superficie y el 4,5 en el número de ferias.

\section{Recintos feriales}

Cuando comienza a analizarse el sector ferial en Asia-Pacífico en 2005 se detecta que $\triangle$ 
CUADRO 9

EVOLUCIÓN DE LOS INGRESOS ESTIMADOS GENERADOS POR LA ACTIVIDAD FERIAL EN ASIA-PACÍFICO EN 2004-2014

\begin{tabular}{|c|c|c|c|c|c|c|}
\hline \multirow{2}{*}{ Países } & \multicolumn{6}{|c|}{ Ingresos estimados (USD) } \\
\hline & 2004 & 2005 & 2006 & 2007 & 2008 & 2009 \\
\hline China .............................. & 623.007 .500 & 670.715 .250 & 759.823 .000 & 1.115 .794 .500 & 1.334 .142 .000 & 1.136 .310 .500 \\
\hline Japón........................ & 593.865 .500 & 600.264 .250 & 648.069 .250 & 778.899 .000 & 744.979 .250 & 816.095 .250 \\
\hline Corea del Sur ......... & 142.175 .000 & 145.250 .250 & 131.792 .500 & 210.800 .500 & 187.000 .000 & 228.267 .000 \\
\hline Hong Kong ............. & 191.122 .750 & 202.900 .250 & 323.444 .000 & 321.521 .250 & 330.362 .250 & 331.394 .500 \\
\hline India............................ & 68.961 .750 & 63.887 .000 & 128.437 .750 & 165.173 .250 & 161.435 .500 & 157.248 .250 \\
\hline Australia ..................... & nd & nd & 154.600 .250 & 188.839 .500 & 172.700 .750 & 175.966 .750 \\
\hline Taiwán .......................... & 63.502 .250 & 72.201 .750 & 85.874 .750 & 76.410 .750 & 81.647 .750 & 86.551 .000 \\
\hline Tailandia ................... & 43.839 .250 & 66.889 .750 & 110.721 .750 & 116.838 .000 & 145.262 .000 & 149.389 .750 \\
\hline Singapur ........................ & 55.640 .000 & 64.076 .250 & 64.023 .750 & 78.849 .750 & 85.878 .000 & 93.110 .500 \\
\hline Indonesia .................... & 30.475 .500 & 34.755 .500 & 25.502 .000 & 41.385 .000 & 43.131 .500 & 43.505 .000 \\
\hline Filipinas …………........ & 25.585 .250 & 21.572 .500 & 18.631 .000 & 15.973 .500 & 15.565 .000 & 15.816 .500 \\
\hline Malasia ........................ & 28.328 .750 & 38.680 .250 & 70.907 .750 & 75.118 .750 & 73.388 .000 & 75.815 .250 \\
\hline Pakistán....................... & 10.506 .000 & 11.401 .000 & 17.311 .500 & 19.333 .750 & 18.123 .250 & 18.200 .750 \\
\hline Vietnam ………........... & 8.228 .250 & 16.874 .750 & 28.260 .500 & 31.427 .250 & 41.639 .250 & 41.942 .500 \\
\hline Macao........................ & nd & nd & nd & 10.805 .750 & 17.234 .250 & 24.525 .500 \\
\hline Total .......................... & 1.885 .237 .750 & 2.009 .468 .750 & 2.567.399.750 & 3.247 .170 .500 & 3.452 .488 .750 & 3.394 .139 .000 \\
\hline
\end{tabular}

CUADRO 9 (continuación)

EVOLUCIÓN DE LOS INGRESOS ESTIMADOS GENERADOS POR LA ACTIVIDAD FERIAL EN ASIA-PACíFICO EN 2004-2014

\begin{tabular}{|c|c|c|c|c|c|c|c|}
\hline \multicolumn{8}{|c|}{ Ingresos estimados (USD) } \\
\hline Países & 2010 & 2012 & 2013 & 2014 & $\begin{array}{l}\text { Porcentaje } \\
\text { s/total } 2014\end{array}$ & $\begin{array}{l}\text { Variación } \\
14 / 04(\%)^{1}\end{array}$ & $\begin{array}{c}\text { Incremento } \\
\text { medio anual (\%) }\end{array}$ \\
\hline 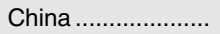 & 1.209 .369 .000 & 1.455 .479 .000 & 1.571 .920 .000 & 1.691 .122 .500 & 35,9 & 171,4 & 12,8 \\
\hline Japón...................... & 796.698 .000 & 919.278 .000 & 937.666 .750 & 961.527 .500 & 20,4 & 61,9 & 5,8 \\
\hline Corea del Sur ........ & 236.268 .000 & 242.404 .500 & 249.680 .500 & 277.749 .500 & 5,9 & 95,4 & 9,3 \\
\hline Hong Kong ............. & 384.189 .250 & 391.113 .250 & 402.849 .000 & 414.553 .000 & 8,8 & 116,9 & 10,2 \\
\hline India......................... & 162.354 .000 & 178.642 .000 & 187.577 .000 & 201.587 .000 & 4,3 & 192,3 & 15,9 \\
\hline Australia ................. & 179.099 .000 & 253.971 .250 & 261.593 .250 & 269.070 .750 & 5,7 & 74,0 & 9,3 \\
\hline Taiwán ................... & 97.821 .750 & 153.212 .000 & 171.344 .750 & 186.282 .500 & 4,0 & 193,3 & 13,9 \\
\hline Tailandia ................ & 132.638 .250 & 147.245 .000 & 174.411 .500 & 188.992 .000 & 4,0 & 331,1 & 19,7 \\
\hline Singapur ................ & 103.420 .250 & 151.748 .000 & 197.680 .000 & 197.900 .750 & 4,2 & 255,7 & 16 \\
\hline Indonesia................. & 44.803 .500 & 46.864 .750 & 49.678 .500 & 60.478 .250 & 1,3 & 98,4 & 10,0 \\
\hline Filipinas .................... & 22.931 .000 & 24.212 .250 & 24.940 .000 & 26.872 .750 & 0,6 & 5,0 & 1,9 \\
\hline Malasia ..................... & 87.346 .500 & 106.083 .500 & 103.263 .000 & 109.712 .250 & 2,3 & 287,3 & 18,6 \\
\hline Pakistán................... & 18.629 .750 & 19.784 .750 & 20.577 .250 & 21.483 .000 & 0,5 & 104,5 & 8,3 \\
\hline Vietnam .................... & 42.317 .250 & 45.378 .000 & 47.195 .750 & 50.148 .500 & 1,1 & 509,5 & 26,2 \\
\hline Macao....................... & 32.339 .000 & 18.005 .250 & 18.138 .500 & 49.306 .000 & 1,0 & 356,3 & 43,7 \\
\hline$\ldots \ldots \ldots \ldots \ldots \ldots$ & 3.550 .224 .500 & 4.153.421.500 & 4.418.515.750 & 4.706.786.250 & 100,0 & 149,7 & 11,1 \\
\hline
\end{tabular}

desde cinco años antes ya se había producido una explosión en el espacio ferial, lo que significaba que se había pasado de una situación en la que la principal preocupación para el sector era el constreñimiento del espacio, a otra en la que preocupaba la proliferación de eventos compitiendo entre sí y la caída de precios (UFI-BSG, 2005). Continuando con dicha tendencia, el número de recintos feriales en AsiaPacífico siguen registrando un notable crecimiento entre 2005 y 2015, y, en paralelo, la superficie de exposición cubierta disponible, como puede apreciarse en el Cuadro 10. En las publicaciones de UFI-BSG, se indica que sus datos se refieren a los recintos construidos para la celebración de ferias y de posible interés para los operadores internacionales, no a todas las instalaciones en las que se llevan a cabo eventos. La UFI (2007) estima que en 2006 Asia-Pacífico contaba con un total de 4,2 millones de $\mathrm{m}^{2}$, el 15 por 100 de la superficie disponible mundial, y a finales de 2011, dicha asociación, eleva esa misma magnitud a 6,6 millones de $\mathrm{m}^{2}$, es decir el 20 por 100 de cuota global (UFI, 2014). 




\begin{tabular}{|c|c|c|c|c|c|c|c|c|c|c|}
\hline \multirow[b]{2}{*}{ Países } & \multicolumn{2}{|c|}{2009} & \multicolumn{2}{|c|}{2010} & \multicolumn{2}{|c|}{2011} & \multicolumn{2}{|c|}{2012} & \multicolumn{2}{|c|}{2013} \\
\hline & Recintos & $\begin{array}{l}\text { Superficie } \\
\qquad\left(\mathrm{m}^{2}\right)\end{array}$ & Recintos & $\begin{array}{c}\text { Porcentaje } \\
\text { s/total }\end{array}$ & Recintos & $\begin{array}{l}\text { Superficie } \\
\qquad\left(\mathrm{m}^{2}\right)\end{array}$ & Recintos & $\begin{array}{l}\text { Superficie } \\
\qquad\left(m^{2}\right)\end{array}$ & Recintos & $\begin{array}{c}\text { Superficie } \\
\qquad\left(\mathrm{m}^{2}\right)\end{array}$ \\
\hline China ................. & 87 & 3.634 .489 & 95 & 4.113 .520 & 96 & 4.176 .258 & 97 & 4.419 .382 & 101 & 4.533.782 \\
\hline Japón ................ & 12 & 350.606 & 12 & 350.606 & 12 & 350.606 & 12 & 350.606 & 13 & 355.658 \\
\hline Corea del Sur ............. & 12 & 223.326 & 12 & 223.326 & 12 & 286.784 & 12 & 308.368 & 12 & 308.368 \\
\hline 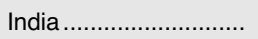 & 12 & 257.457 & 12 & 257.457 & 12 & 257.457 & 13 & 285.457 & 13 & 285.457 \\
\hline 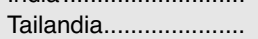 & 7 & 209.905 & 7 & 209.905 & 8 & 212.405 & 9 & 222.405 & 9 & 222.984 \\
\hline Singapur . & 4 & 203.600 & 4 & 203.600 & 4 & 203.600 & 4 & 203.600 & 4 & 219.970 \\
\hline Taiwán.............................. & 4 & 105.409 & 4 & 105.409 & 4 & 105.409 & 4 & 105.409 & 4 & 99.278 \\
\hline Indonesia ....................... & 3 & 31.656 & 3 & 31.656 & 3 & 31.656 & 8 & 56.094 & 8 & 56.094 \\
\hline Hong Kong.................. & 3 & 151.920 & 3 & 151.920 & 3 & 151.920 & 3 & 151.920 & 2 & 149.820 \\
\hline 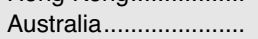 & 8 & 115.242 & 8 & 115.242 & 8 & 115.242 & 10 & 139.242 & 10 & 139.242 \\
\hline Malasia ......................... & 4 & 71.292 & 4 & 71.292 & 4 & 71.292 & 4 & 71.292 & 4 & 71.292 \\
\hline  & 2 & 76.715 & 2 & 76.715 & 2 & 76.715 & 2 & 76.715 & 2 & 76.715 \\
\hline Paquistán .................... & 2 & 39.045 & 2 & 39.045 & 2 & 39.045 & 2 & 39.045 & 2 & 39.045 \\
\hline 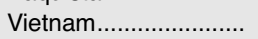 & 4 & 33.793 & 4 & 33.793 & 4 & 33.793 & 4 & 33.793 & 4 & 33.793 \\
\hline Filipinas........................... & 1 & 8.300 & 3 & 26.257 & 3 & 26.257 & 3 & 26.257 & 3 & 26.257 \\
\hline Total . & 165 & 5.512 .755 & 175 & 6.009 .743 & 177 & 6.138 .439 & 187 & 6.489 .585 & 191 & 6.617 .755 \\
\hline
\end{tabular}

\begin{tabular}{|c|c|c|c|c|c|c|c|c|c|c|}
\hline \multirow{2}{*}{ Países } & \multicolumn{2}{|c|}{2014} & \multicolumn{4}{|c|}{2015} & \multicolumn{2}{|c|}{$2015 / 2005^{1}$} & \multirow{2}{*}{$\begin{array}{l}\text { Crecimiento } \\
\text { medio anual } \\
\text { recintos (\%) }\end{array}$} & \multirow{2}{*}{$\begin{array}{c}\text { Crecimiento } \\
\text { medio anual } \\
\text { superficie } \\
\text { (\%) }\end{array}$} \\
\hline & Recintos & $\begin{array}{l}\text { Superficie } \\
\text { (m2) }\end{array}$ & Recintos & $\begin{array}{c}\text { Porcentaje } \\
\text { s/total }\end{array}$ & $\begin{array}{l}\text { Superficie } \\
\qquad\left(\mathrm{m}^{2}\right)\end{array}$ & $\begin{array}{c}\text { Porcentaje } \\
\text { s/total }\end{array}$ & $\begin{array}{l}\text { Variación } \\
\text { s/recintos }\end{array}$ & $\begin{array}{c}\text { Variación } \\
\text { s/superficie }\end{array}$ & & \\
\hline China ............................ & 106 & 4.845 .192 & 108 & 52,4 & 5.575 .692 & 70,9 & 89,5 & 149,2 & 6,8 & 10,2 \\
\hline Japón ........................... & 13 & 355.658 & 14 & 6,8 & 358.658 & 4,6 & 16,7 & 1,4 & 1,6 & 0,3 \\
\hline Corea del Sur ............. & 13 & 324.368 & 13 & 6,3 & 324.368 & 4,1 & 160 & 155 & 12,8 & 10,5 \\
\hline  & 14 & 290.457 & 16 & 7,8 & 319.892 & 4,1 & 60 & 30,8 & 4,9 & 2,8 \\
\hline Tailandia...................... & 9 & 222.984 & 9 & 4,4 & 222.984 & 2,8 & 125 & 19,5 & 8,8 & 1,8 \\
\hline Singapur ....................... & 4 & 219.970 & 4 & 1,9 & 219.970 & 2,8 & 100 & 161,9 & 8,3 & 11,2 \\
\hline Taiwán......................... & 5 & 117.178 & 5 & 2,4 & 154.818 & 2,0 & 66,7 & 58,4 & 7,5 & 10,4 \\
\hline Indonesia .................... & 9 & 106.094 & 10 & 4,9 & 154.694 & 2,0 & 400 & $1.207,1$ & 24 & 37,3 \\
\hline Hong Kong................... & 2 & 149.820 & 2 & 1,0 & 149.820 & 1,9 & $-33,3$ & 13,4 & $-3,3$ & 1,4 \\
\hline Australia....................... & 10 & 137.042 & 10 & 4,9 & 137.042 & 1,7 & 42,9 & 27 & 4,9 & 3,2 \\
\hline Malasia ....................... & 4 & 71.292 & 4 & 1,9 & 71.292 & 0,9 & 100,0 & 44,8 & 8,3 & 4,1 \\
\hline Macao ........................... & 2 & 76.715 & 2 & 1,0 & 76.715 & 1,0 & 0,0 & 0 & 0,0 & 0,0 \\
\hline Paquistán...................... & 2 & 39.045 & 2 & 1,0 & 37.191 & 0,5 & 100,0 & 455,9 & 10,0 & 38,1 \\
\hline Vietnam........................ & 4 & 33.793 & 4 & 1,9 & 33.793 & 0,4 & 300,0 & 373,7 & 20,0 & 23,5 \\
\hline Filipinas......................... & 3 & 26.257 & 3 & 1,5 & 26.257 & 0,3 & 200,0 & 216,3 & 20,0 & 21,6 \\
\hline Total . & 200 & 7.015 .865 & 206 & 100,0 & 7.863.186 & 100,0 & 100,0 & 121,7 & 7,4 & 8,5 \\
\hline
\end{tabular}




\begin{tabular}{|c|c|c|c|}
\hline \multicolumn{4}{|c|}{$\begin{array}{l}\text { CUADRO } 11 \\
\text { MAYORES RECINTOS FERIALES DEL MUNDO }{ }^{1}\end{array}$} \\
\hline Recinto ferial & $\begin{array}{l}\text { Capacidad } \\
\left(\mathrm{m}^{2}\right)\end{array}$ & Recinto ferial & $\begin{array}{l}\text { Capacidad } \\
\left(\mathrm{m}^{2}\right)\end{array}$ \\
\hline 1. Hannover Exhibition Center ....................... & 463.275 & 27. IMPACT Muang Thong Thani Bangkok......................... & 140.000 \\
\hline  & 366.637 & 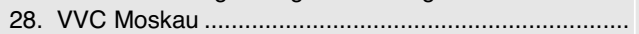 & 132.720 \\
\hline 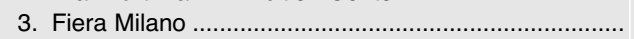 & 345.000 & 29. Georgia World Congress Center Atlanta...................... & 130.112 \\
\hline 4. China Import \& Export Fair Complex Guangzhou ....... & 340.000 & 30. BVV Veletrhy Brno & 121.314 \\
\hline 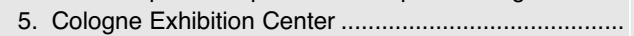 & 284.000 & 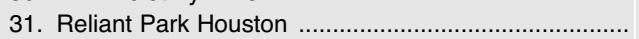 & 120.402 \\
\hline 6. Dusseldorf Exhibition Center................. & 262.218 & 32. Fiera del Levante Bari............... & 120.000 \\
\hline 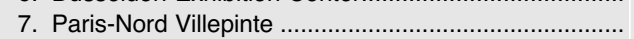 & 242.582 & 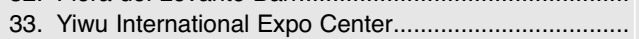 & 120.000 \\
\hline 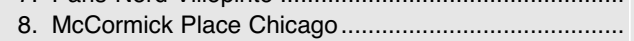 & 241.549 & 34. Fiera Roma & 118.910 \\
\hline 9. Fira Barcelona - Gran Via ................................. & 240.000 & 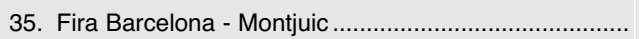 & 115.211 \\
\hline 10. Feria Valencia & 230.837 & 36. Brussels Expo & 114.445 \\
\hline 11. Paris Porte de Versailles ................................... & 227.380 & 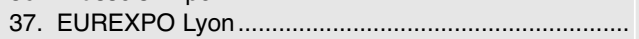 & 114.275 \\
\hline 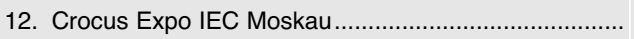 & 226.399 & 38. Leipzig Exhibition Center ................... & 111.300 \\
\hline 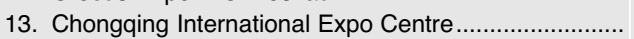 & 204.000 & 39. Essen Exhibition Center & 110.000 \\
\hline 14. The NEC Birmingham & 201.634 & 40. Singapore Expo & 109.187 \\
\hline 15. BolognaFiere & 200.000 & 41. Rimini Fiera & 109.000 \\
\hline  & 200.000 & 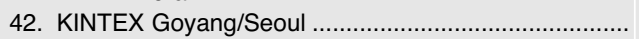 & 108.483 \\
\hline 17. SNIEC Shanghai & 200.000 & 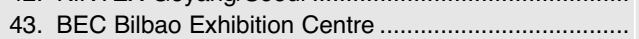 & 108.000 \\
\hline 18. Orange County Convention Center Orlando................ & 190.875 & 44. Palexpo Genf & 108.000 \\
\hline 19. Las Vegas Convention Center ............................ & 184.456 &  & 107.654 \\
\hline 20 Munich Exhibition Center …………………….... & 180.000 & 46. New China Int. Exhibition Center Beijing .................... & 106.800 \\
\hline 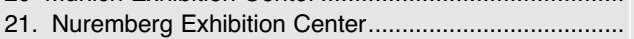 & 170.000 & 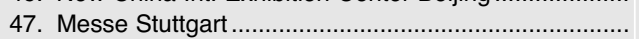 & 105.200 \\
\hline 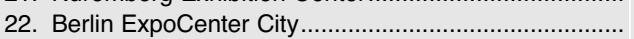 & 170.000 & 48. Shenyang International Exhibition Center.................... & 105.200 \\
\hline 23. Veronafiere & 151.536 & 49. Shenzhen Convention \& Exhibition Center.................. & 105.000 \\
\hline 24 National Exhibition \& Convention Center (Shanghai).. & 150.000 & 50. Ernest N. Morial Convention Center New Orleans ...... & 102.230 \\
\hline 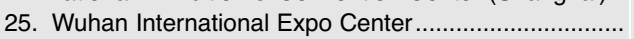 & 150.000 & 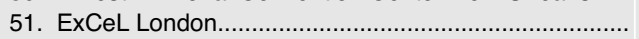 & 100.000 \\
\hline 26. Messe Basel. & 141.000 &  & 100.000 \\
\hline
\end{tabular}

En 2005, la cifra total de recintos ascendía a 103 y la superficie disponible de los mismos era de 3,54 millones de $\mathrm{m}^{2}$. En 2015 el número de recintos contabilizados se eleva a 206 (100 por 100) y la capacidad disponible a 7,86 millones de $\mathrm{m}^{2}$ (121,7 por 100). El crecimiento medio anual, en el primer caso, es del 7,4 por 100 , y del 8,5 por 100 en el de la superficie disponible, porcentaje similar al del crecimiento medio anual de la ocupación (8,8 por 100) mencionado en el apartado 2. De ambos parámetros corresponde a China el 52,4 y el 70,9 por 100 , respectivamente, país que ha visto crecer la cifra de los primeros y, consecuentemente, la superficie de exposición, año tras año, hasta alcanzar los 108 (89,5 por 100), con una superficie de 5,57 millones de $\mathrm{m}^{2}$ (149,2 por 100). El peso de este país sobre el conjunto también ha variado. En 2005 el número de recintos de China suponía el 55,3 por 100 del total, casi tres puntos porcentuales menos, $y$ el 63,1 por 100 de la superficie disponible conjunta, significando ello un incremento de cerca de ocho puntos porcentuales. Un fuerte crecimiento en el número de recintos se produce entre 2007 y 2010, pasando de 66 a 95, y de 2,42 millones a 4,11 millones de $\mathrm{m}^{2}$ en tan solo tres años. China es el segundo país del mundo con mayor capacidad de exposición, tras los EEUU (UFI, 2014).

El crecimiento en ambas variables se registra también en otros países, como Indonesia, que pasa de 2 a 10 recintos entre 2005 y 2015 (400 por 100) y de 11.800 a $154.694 \mathrm{~m}^{2}$ (1.207 por 100), aunque ello suponga que el país cuente solamente con el 5 por 100 de los recintos de la zona y con el 2 por 100 de la superficie total disponible.

También han sufrido importantes incrementos relativos Vietnam, Filipinas y Paquistán, entre 2005 y 2015. Los tres presentan aumentos en el número de recintos del 300,200 y 100 por 100, respectivamente, ya que tenían un solo recinto, e incrementos en la superficie $\square$ 
disponible del 373,7 , del 216,3 y del 455,9 por 100 , alcanzando los $34.000,26.000$ y 37.000 $\mathrm{m}^{2}$, pero en ambos conceptos siguen teniendo escaso peso relativo, pues los tres países partían de cifras muy pequeñas y continúan situándose al final de la tabla. Japón es el segundo país con mayor peso en materia de ferias, a mucha distancia de China, pero cuenta con $358.600 \mathrm{~m}^{2}$, es decir el 4,6 por 100 del total (10 por 100 en 2005). Durante la década analizada no ha registrado variaciones significativas en términos relativos, sumando dos recintos más a los 12 con que contaba en 2005. Corea del Sur, tercer país en términos de superficie disponible actualmente, pasó de 5 a 13 recintos en la década (160 por 100), y de 127.200 a $324.300 \mathrm{~m}^{2}$ (155 por 100).

Por otra parte, en el Cuadro 11 puede observarse cómo 12 de estos recintos asiáticos (23 por 100), aparecen entre los mayores del mundo. Dicho cuadro muestra los 52 recintos con superficies superiores a $100.000 \mathrm{~m}^{2}$ brutos de exposición cubierta. Nueve de estos se encuentran en China y los otros 3 en Tailandia, Singapur y Corea del Sur. El mayor de los recintos asiáticos, inaugurado en 2002 , es el de Guangzhou que, con $340.000 \mathrm{~m}^{2}$, es el cuarto mayor del mundo, y otros dos recintos, situados en Chongqing y en Shanghái, superan los $200.000 \mathrm{~m}^{2}$. 34 de los recintos feriales de dicha relación se encuentran en Europa (el 65,4 por 100), incluyendo 4 situados en Europa Central y del Este. Los 6 restantes (11,5 por 100) se encuentran en EEUU.

En 2006, los recintos de $100.000 \mathrm{~m}^{2}$ o más en todo el mundo eran 43 , entre los cuales había cinco en Asia-Pacífico, tres localizados en China, el de Guangzhou, que disponía de $149.000 \mathrm{~m}^{2}$, el de Shenzhen y el de Shanghái (SNIEC), que entonces tenía $103.500 \mathrm{~m}^{2}$. También se encontraba entre los mayores recintos el de Tailandia (IMPACT) y el de Singapur (EXPO), con $100.000 \mathrm{~m}^{2}$ (AUMA, 2006).
En 2016, está previsto que siete países añadan capacidad de exposición: Australia, China, Indonesia, Malasia, Paquistán, Tailandia y Taiwán. La superficie de exposición de este último crecerá un 32 por 100, en Australia se inaugurará un nuevo recinto en Sídney y la capacidad expositiva de China crecerá un 15 por 100, comparando las cifras del final de 2014 con las de final de 2016 (UFI-BSG, 2015).

\section{Conclusiones}

De los diferentes aspectos analizados, pueden derivarse las siguientes conclusiones.

La cuota de Asia-Pacífico sobre el total mundial, en términos de ocupación por la actividad ferial, con datos de 2012, se sitúa en el 17,4 por 100 , mientras que la de Europa es del 37,3 por 100 y la de Norteamérica -EEUU y Canadá- del 38,4 por 100 .

El número de ferias del conjunto de países de Asia-Pacífico entre 2004 y 2014 se incrementó un 22 por 100 (crecimiento anual medio del 2,3 por 100), alcanzando la cifra de 2.132 eventos. El crecimiento en la superficie ocupada fue del 127,7 por 100, llegando a alcanzar el último año $18.641 .750 \mathrm{~m}^{2}$. Dicho crecimiento, conjuntamente, se produce año tras año sin excepción.

China, con 619 ferias en 2014, reúne el 29 por 100 del total y el 56 por 100 de la superficie ocupada, con 10,4 millones de $\mathrm{m}^{2}$. A Japón, el segundo país con mayor actividad, corresponde un 15,9 por 100 de las ferias, 338, y un 11 por 100 de la superficie total. La ocupación conjunta de los cinco primeros países por dicho concepto, China, Japón, Corea, Hong Kong e India, representa casi el 82 por 100 del total. El crecimiento medio anual conjunto en la década, en términos de ocupación, es del 8,8 por 100 .

La actividad ferial en Asia-Pacífico asignada a los organizadores de fuera de la región es $D$ 
relevante. Las entidades alemanas llevan a cabo anualmente más de 300 ferias fuera de su país, de las cuales, más del 50 por 100 tienen lugar en Asia-Pacífico, fundamentalmente en China, en segundo lugar en India, así como en Japón, Indonesia, Tailandia, Vietnam, Australia, Singapur, Taiwán, Hong Kong y Macao. Ello pone de manifiesto el interés de dichos organizadores y el de las empresas, a través de las ferias, por esos mercados.

Entre todas las ferias celebradas, no puede decirse que haya grandes variaciones en materia de sectores en el periodo 2004-2014. Los sectores de ingeniería y productos industriales y de productos terminados en general, superan el 10 por 100 del espacio ocupado por las ferias en la región. El sector del mueble e interiorismo está ligeramente por debajo del 10 por $100 \mathrm{y}$ otros siete sectores alcanzan un porcentaje entre el 5 y el 10 por 100: electrónica y componentes, textiles, ropa y moda; alimentación, bebidas y hospitality; ocio, hobby y entretenimiento; automóviles y motocicletas; construcción e infraestructuras y productos premium, hogar, regalos y juguetes.

Los ingresos producidos por la actividad ferial en la década sufren un incremento próximo al 150 por 100 para el conjunto de países de Asia-Pacífico, pasando de 1.885 millones de dólares en 2004 a cerca de 4.707 millones de dólares en 2014 (11,1 por 100 de crecimiento medio anual). En términos relativos, destacan: Vietnam (509,5 por 100), Macao $(356,3)$, Tailandia $(331,1)$, Malasia $(287,3)$, Taiwán $(193,3)$, India $(192,3)$ y China $(171,4)$. China, con 1.691 millones de dólares de ingresos estimados en 2014, reúne el 35,9 por 100 sobre el total, a pesar de suponer el 56 por 100 de la superficie global y el 29 por 100 de las ferias. Japón, con 961 millones de dólares de ingresos en 2014, representa un 20,4 por 100 sobre el total. Hong Kong, con 414,5 millones de dólares, supone el 8,8 por 100 de los ingresos globales estimados para la región.
El número de los recintos feriales situados en Asia-Pacífico ha registrado un notable crecimiento y, consecuentemente, la superficie de exposición disponible, lo que supone asimismo una extraordinaria inversión. En 2005 la cifra total de recintos ascendía a 103 y su superficie global disponible era de 3,54 millones de $\mathrm{m}^{2}$. En 2015 el número de recintos asciende a 206 y la capacidad disponible total se eleva a 7,86 millones de $\mathrm{m}^{2}$ (121,7 por 100). Ello supone un crecimiento medio anual conjunto del 7,4 por 100 en el primer parámetro y del 8,5 en el segundo.

Con datos de 2015, corresponde a China el 52,4 y el 70,9 por 100 , respectivamente, del total, país que ha crecido, año tras año, hasta alcanzar los 108 recintos $(89,5$ por 100$)$ y una superficie de 5,57 millones de $\mathrm{m}^{2}$ (149,2 por 100). En 2005 sus recintos representaban el 55,3 por 100 y el 63,1 por 100 de la superficie disponible conjunta. China ya es el segundo país del mundo por capacidad ferial y por actividad en términos de ocupación. Dispone de una capacidad 15 veces mayor que la de Japón. Éste, segundo país de Asia-Pacífico en materia de ferias, cuenta con $358.600 \mathrm{~m}^{2}$ de espacio expositivo en 2015 , el 4,6 por 100 del total, frente al 10 por 100 en 2005. En dicho periodo únicamente suma 2 recintos más a los 12 con que contaba el primer año. Corea del Sur, el tercer país en términos de superficie disponible actualmente, pasó de 5 a 13 recintos en la década, y de 127.200 a $324.300 \mathrm{~m}^{2}$. Un crecimiento significativo en materia de recintos también se observa en Indonesia, que pasa de 2 a 10 entre 2005 y 2015 y de 11.800 a $154.694 \mathrm{~m}^{2}$.

12 de los 52 mayores recintos del mundo, con superficies superiores a $100.000 \mathrm{~m}^{2}$ brutos de exposición cubierta, se encuentran en AsiaPacífico. De ellos, 9 en China, y los otros 3 en Tailandia, Singapur y Corea del Sur. El mayor de los recintos asiáticos es el de Guangzhou que, con $340.000 \mathrm{~m}^{2}$, es el cuarto mayor del mundo. Otros dos, en Chongqing y en Shanghái, superan los $200.000 \mathrm{~m}^{2}$. 
En definitiva, Asia-Pacífico cuenta con una infraestructura muy relevante para la celebración de ferias, que se ha ido adecuando a las necesidades generadas por el crecimiento de la actividad ferial en la región. La mitad de los recintos se han construido en la última década y son, por tanto, edificaciones actuales. Además, ya cuenta con un número considerable de recintos de gran tamaño, que les permite acoger eventos de grandes dimensiones o dar cabida a varios certámenes simultáneamente. A pesar de dicho crecimiento del número de recintos y de la capacidad expositiva, en términos porcentuales aún ha crecido más la ocupación debida a la celebración de ferias (aunque no el número de éstas, que han registrado un incremento moderado) y, sobre todo, los ingresos derivados de esta actividad.

Tras ver la evolución de los diferentes elementos analizados en materia de ferias, cuyo crecimiento incluso supera al de la economía de Asia-Pacífico en términos globales, salvo en el número de ferias, cabe prever para dicha área un crecimiento sostenido en los próximos años en paralelo al desarrollo económico de los diferentes países.

\section{Bibliografía}

[1] AUMA (2002). The German Trade Fair Industry 2001-2002. Ausstellungs- und Messe-Ausschuss der Deutschen Wirtschaft e.V. Berlín.

[2] AUMA (2006). German Trade Fair Industry Review 2005. Ausstellungs- und MesseAusschuss der Deutschen Wirtschaft e.V. Berlín.

[3] AUMA (2010). Die Messewirtschaft - Bilanz 2009. Ausstellungs- und Messe-Ausschuss der Deutschen Wirtschaft e.V. Berlín.

[4] AUMA (2015a). German Trade Fair Industry Review 2014, Ausstellungs- und MesseAusschuss der Deutschen Wirtschaft e.V., Berlín. Disponble en: www.auma.de

[5] AUMA (2015b). German Trade Fair Quality Abroad 2016, Ausstellungs- und MesseAusschuss der Deutschen Wirtschaft e.V., Berlín. Disponible en: www.auma.de
[6] CARRERAS, A. y TORRA, L. (2004). Història Econòmica de les Fires a Catalunya, Barcelona: Departament de Comerç, Turisme i Consum. Generalitat de Catalunya.

[7] GODAR, S. y O'CONNOR, P. (2001). «Same Time Next Year - Buyer Trade Show Motives». Industrial Marketing Management, vol. 30, $n^{\circ} 1$, pp. 77-86.

[8] JIMENEZ, J. F.; CAZORLA, I. M. y LINARES, E. (2002). «Ferias Comerciales en España. Un análisis sectorial». Distribución y Consumo, $n^{\circ} 61$, enero-febrero, pp 61-71.

[9] LLUCH, L.B. (1982). Crónica de los primeros 65 años / 1917-1982, Tomo I, Feria Muestrario Internacional de Valencia.

[10] MESONERO, M. (2004). «Identificación de las variables explicativas del éxito obtenido en una feria industrial». XVI Encuentro de profesores universitarios de marketing, Alicante, septiembre, pp 621-637.

[11] MUNUERA, J. L.; RUIZ, S.; HERNÁNDEZ, M. y MAS, F. (1993). «Las ferias comerciales como variable de marketing: análisis de los objetivos del expositor». Información Comercial Española. Revista de Economía, 718, junio, pp. 119-137.

[12] MUNUERA, J. L.; HERNÁNDEZ, M. y RUIZ, S. (1995). «Planificación de las ferias como actividades del marketing». ESIC Market, enero-marzo, pp 9-30.

[13] PUCHALT, J. (2001). Las ferias comerciales como instrumento de marketing al servicio de las empresas: una aplicación a Feria Valencia, Tesis doctoral presentada en la Facultad de Economía de la Universidad de Valencia.

[14] PUCHALT, J. (2008). «La actividad ferial en el contexto europeo». Información Comercial Española. Revista de Economía, $n^{\circ} 840$, enero-febrero, pp 29-50, Madrid.

[15] PUCHALT, J. y MUNUERA, J.L. (2008). «Panorama internacional de las ferias comerciales». Información Comercial Española. Revista de Economía, ${ }^{\circ}$ 840, enero-febrero, pp. 7-28, Madrid.

[16] STEVENS, R. P. (2005). Trade show and Event Marketing, Thomson y American Marketing Association, Mason (Ohio).

[17] UFI (2007). The World Map of Exhibition Venues and future trends. October. Paris: The Global Association of the Exhibition Industry.

[18] UFI (2014). Global Exhibition Industry Statistics - March 2014, The Global Association of the Exhibition Industry, Paris. Disponible en: www.ufi.org 
[19] UFI-BSG (2005). The Trade Fair Industry in Asia -Executive Summary-. Hong-Kong: The Global Association of the Exhibition Industry Business Strategies Group Ltd.

[20] UFI-BSG (2006). The Trade Fair Industry in Asia, 2nd edition -Executive Summary-. HongKong: The Global Association of the Exhibition Industry - Business Strategies Group Ltd.

[21] UFI-BSG (2007). The Trade Fair Industry in Asia, 3rd edition -Executive Summary-. HongKong: The Global Association of the Exhibition Industry - Business Strategies Group Ltd.

[22] UFI-BSG (2008). The Trade Fair Industry in Asia, 4th edition -Executive Summary-. HongKong: The Global Association of the Exhibition Industry - Business Strategies Group Ltd.

[23] UFI-BSG (2009). The Trade Fair Industry in Asia, 5th edition -Executive Summary-. Hong- Kong: The Global Association of the Exhibition Industry - Business Strategies Group Ltd.

[24] UFI-BSG (2010). The Trade Fair Industry in Asia, 6th edition -Executive Summary-. Hong-
Kong: The Global Association of the Exhibition Industry - Business Strategies Group Ltd.

[25] UFI-BSG (2011). The Trade Fair Industry in Asia, 7th edition -Executive Summary-. HongKong: The Global Association of the Exhibition Industry - Business Strategies Group Ltd.

[26] UFI-BSG (2012). The Trade Fair Industry in Asia, 8th edition -Executive Summary-. HongKong: The Global Association of the Exhibition Industry - Business Strategies Group Ltd.

[27] UFI-BSG (2013): The Trade Fair Industry in Asia, 9th edition -Executive Summary-. HongKong. The Global Association of the Exhibition Industry - Business Strategies Group Ltd.

[28] UFI-BSG (2014). The Trade Fair Industry in Asia, 10th edition -Executive Summary-. Hong-Kong: The Global Association of the Exhibition Industry - Business Strategies Group Ltd.

[29] UFI-BSG (2015). The Trade Fair Industry in Asia, 11th edition -Executive Summary-. HongKong: The Global Association of the Exhibition Industry - Business Strategies Group Ltd. 


\section{SUSCRIPCIÓN ANUAL}

\begin{tabular}{|c|c|c|c|}
\hline \multicolumn{3}{|c|}{ BOLETÍN ECONÓMICO DE INFORMACIÓN COMERCIAL ESPAÑOLA (12 NÚMEROS) } \\
\hline & $\begin{array}{c}\text { ESPAÑA } \\
1 \text { año }\end{array}$ & $\begin{array}{c}\text { UNIÓN EUROPEA } \\
1 \text { año }\end{array}$ & $\begin{array}{c}\text { RESTO DEL } \\
\text { MUNDO } \\
\text { año }\end{array}$ \\
\hline SUSCRIPCIÓN & $65,00 €$ & $85,00 €$ & $85,00 €$ \\
\hline $\begin{array}{c}\text { Gastos de envío } \\
\text { España }\end{array}$ & $5,76 €$ & $24,36 €$ & $30,00 €$ \\
\hline $\begin{array}{c}\text { Más 4\% de IVA. } \\
\text { Excepto Canarias, Ceuta y Melilla }\end{array}$ & $2,83 €$ & & $115,00 €$ \\
\hline TOTAL & $73,59 €$ & $109,36 €$ & \\
\hline & & & \\
\hline
\end{tabular}

\section{EJEMPLARES SUELTOS}

\section{BOLETÍN ECONÓMICO DE INFORMACIÓN COMERCIAL ESPAÑOLA}

\begin{tabular}{|c|c|c|c|}
\hline & $\begin{array}{l}\text { ESPAÑA } \\
1 \text { ejemplar }\end{array}$ & $\begin{array}{c}\text { UNIÓN EUROPEA } \\
1 \text { ejemplar }\end{array}$ & $\begin{array}{l}\text { RESTO DEL } \\
\text { MUNDO } \\
1 \text { ejemplar }\end{array}$ \\
\hline NÚMERO SUELTO & $7,00 €$ & $9,00 €$ & $9,00 €$ \\
\hline $\begin{array}{l}\text { Gastos de envío } \\
\text { España }\end{array}$ & $0,48 €$ & $2,03 €$ & $2,50 €$ \\
\hline $\begin{array}{c}\text { Más } 4 \% \text { de IVA. } \\
\text { Excepto Canarias, Ceuta y Melilla }\end{array}$ & $0,30 €$ & & \\
\hline TOTAL & $7,78 €$ & $11,03 €$ & $11,50 €$ \\
\hline
\end{tabular}

BOLETÍN ECONÓMICO DE INFORMACIÓN COMERCIAL ESPAÑOLA

\section{DATOS}

Nombre y apellidos

Empresa

Domicilio

D.P.

N.I.F.

Teléf.

Email .

\begin{tabular}{|c|c|c|c|}
\hline & $\begin{array}{c}\text { ESPAÑA } \\
1 \text { ejemplar }\end{array}$ & $\begin{array}{c}\text { UNIÓN EUROPEA } \\
\text { 1 ejemplar } \\
\text { EX́MERO SUELTO }\end{array}$ & $\begin{array}{c}\text { RESTO DEL } \\
\text { MUNDO } \\
\text { ejemplar }\end{array}$ \\
\hline Gastos de envío España & $12,00 €$ & $15,00 €$ & $15,00 €$ \\
\hline $\begin{array}{c}\text { Más 4\% de IVA. } \\
\text { Excepto Canarias, Ceuta y Melilla }\end{array}$ & $0,48 €$ & $2,03 €$ & $2,50 €$ \\
\hline TOTAL & $\mathbf{1 2 , 9 8} €$ & $\mathbf{1 7 , 0 3} €$ & $\mathbf{1 7 , 5 0}$ \\
\hline
\end{tabular}

GOBIERNO DE ESPAÑA
Población

..Fax.
Transferencia a la cuenta de ingresos por venta de publicaciones del Ministerio de Economía y Competitividad.

IBERCAJA. Calle Alcalá 29. 28014 MADRID (ESPAÑA) CÓDIGO CUENTA CLIENTE: 2085-9252-07-0330598330 CÓDIGO BIC DE IBERCAJA: CAZRES2Z IBAN: ES47 2085-9252-07-0330598330

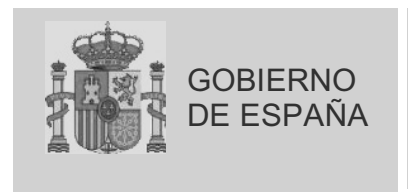

\section{MINISTERIO}

DE ECONOMÍA Y

COMPETITIVIDAD
SUBSECRETARÍA

SECRETARÍA GENERAL TÉCNICA

SUBDIRECCIÓN GENERAL

ESTUDIOS, INFORMACIÓN Y PUBLICACIONES

Suscripciones y ventas por correspondencia:

Paseo de la Castellana, 162 9ª Planta 28046 Madrid. Teléfono 91603 79 93/97

Suscripciones a través de la página web del Ministerio de Economía y Competitividad

distribucionpublicaciones@mineco.es 